\title{
NEEDLE NECROPSY
}

BY

\author{
RICHARD TERRY* \\ From the Dreadnought Seamen's Hospital, Greenwich, and St. Bartholomew's Hospital, London
}

(RECEIVED FOR PUBLICATION JULY 13, 1954)

The importance of post-mortem examination is generally accepted, not only for instruction and research, but also for raising the standard of medical practice. Unfortunately, there are many obstacles. In hospital, necropsies are limited by the natural reluctance of many relatives to give the necessary permission. In nursing homes and private houses, they are seldom performed because of the additional problems of inadequate facilities and lack of time. Correspondence in the British Medical Journal expressed concern at the difficulties of obtaining necropsies on patients dying outside hospital (Loewy, 1953 ; Davies, 1953; Wade, 1953).

It is, however, possible to obtain adequate diagnostic post-mortem specimens with a needle. Such a procedure does not dismay relatives and can be carried out quickly and without trouble with an appropriate instrument. The purpose of this communication is to discuss the technique of needle necropsy and to describe a suitable instrument which has given satisfactory results during the past five years.

\section{Necropsy Instrument}

The instrument is essentially that previously described for needle biopsy of the liver (Terry. 1949) but with a modified needle of larger bore. It consists of a $20 \mathrm{ml}$. syringe adapted to carry a $3 \mathrm{~mm}$. (internal diameter) needle, $15 \mathrm{~cm}$. long, on the barrel and a trocar on the piston (Fig. 1).

The point of the needle is notched and sharpened to ensure that it cuts into the tissue. A bevelled point has been discarded. since it is blunted by hard tissue such as bone, and fails to obtain specimens from spongy tissue such as lung. The trocar has a cutting point, which projects $1 \mathrm{~cm}$. beyond the needle: it is flattened along one side so that pressures within the syringe, positive or negative, are transmitted down the needle to the specimen. A spring-catch on the cap of the syringe engages with notches on the pistonrod and maintains the piston in place after suction has been applied.

\section{Technique of Needle Necropsy}

Needle necropsy can be performed at the bedside as easily as in the mortuary. A pair of rubber gloves

* Present address : Hektoen Institute for Medical Research, Chicago, 12, Illinois, U.S.A. is useful but not essential. Ascitic or pleural fluic will escape through the needle track: suture materiat and cotton-wool should therefore be available to pro: tect the bed and coverings. Several labelled test $\stackrel{\infty}{-}$ tubes containing fixative are necessary for the speciew mens. The danger of personal injury with the needle especially in cases of infection, must be constantlo borne in mind. No other precautions or preparations are necessary.

The instrument is assembled so that the flattenes side of the trocar is adjacent to the notch in the poinf of the needle: if it is adjacent to one of the twe points of the needle, that point will catch in the tissues. The trocar and needle are then inserted through the skin and intervening tissues until ther particular organ or tumour is reached. The specif men is obtained by a movement exactly opposite tôे that used in aspirating fluid with a syringe: the lefp hand holds the plunger stationary, while the righo hand thrusts the syringe barrel forwards towards the cadaver, and so advances the needle into the tissue? The specimen is now within the needle and held $b \vec{b}$ the negative pressure in the syringe, but it is stil $\mathrm{B}$ attached at its distal end. This attachment is brokeq by further withdrawing the plunger to stretch the specimen and then rotating the whole instrumen several times. On removing the instrument from the cadaver, the specimen remains in the distal portiog of the needle. and is prevented by the trocar fron being sucked up into the syringe.

The specimen is best handled by delivering it into a tapered glass tube. After unscrewing the needlo from the syringe the point is inserted into a suitable glass tube and the specimen extruded with an obtup rator. The specimen is kept straighter if the needie is pulled back over the obturator rather than if thres obturator is simply pushed through the needle. The glass tube with its specimen is placed in $10 \%$ formof saline or other fixative in a test-tube. Specimens from different sites are placed in separate labelled tes: tubes (Fig. 2).

\section{Applications}

Needle necropsy is naturally not of equal value in all cases. Diagnosis is easy with a large nodula? liver, whereas it is often impossible in many cord ditions, such as generalized infections, peptic ulce\& ation and its complications, intestinal perforation and obstruction, vascular disasters, and sone cardiac conditions. In general terms, needto 


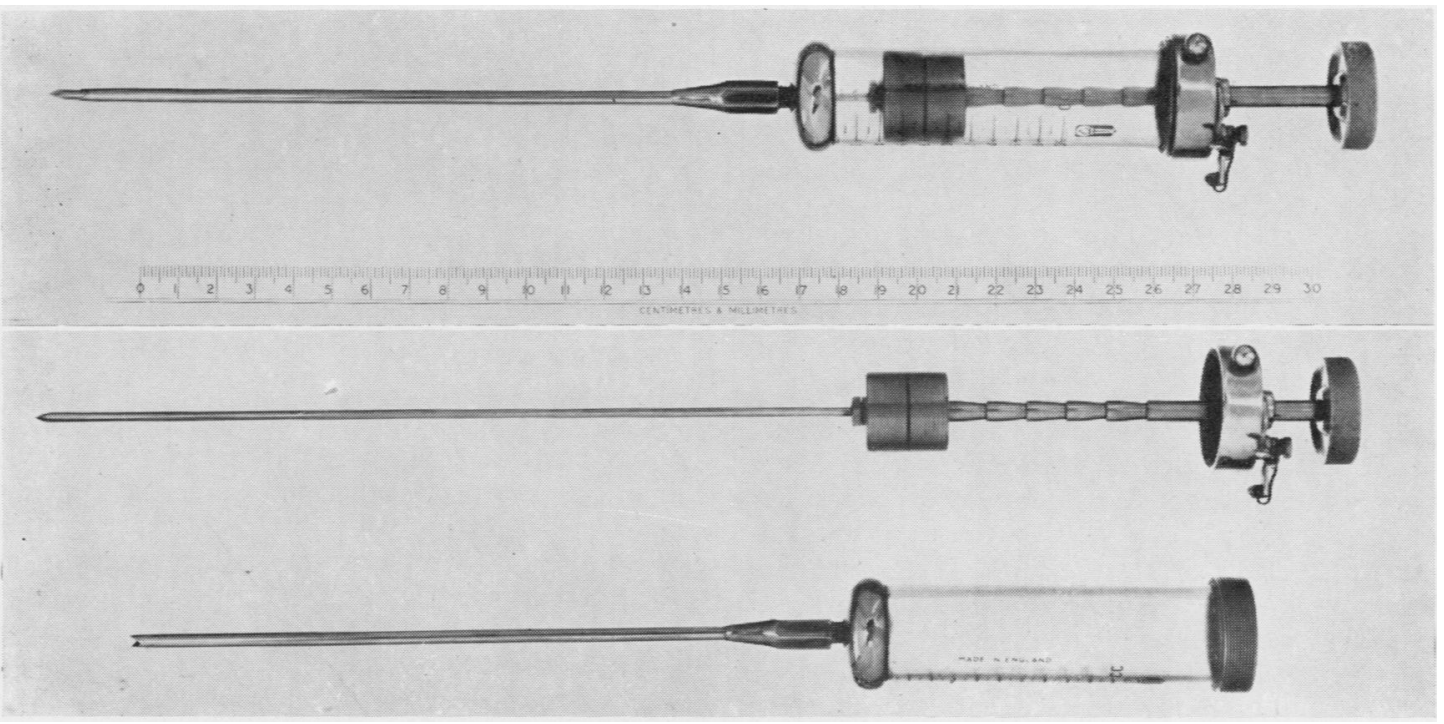

Fig. 1.-Instrument for needle necropsy ready to use (above) and dismantled (below).

necropsy is most likely to be successful when there is a known mass or enlarged viscus.

The brain may sometimes be approached through the foramen magnum, the orbit, or the foramen

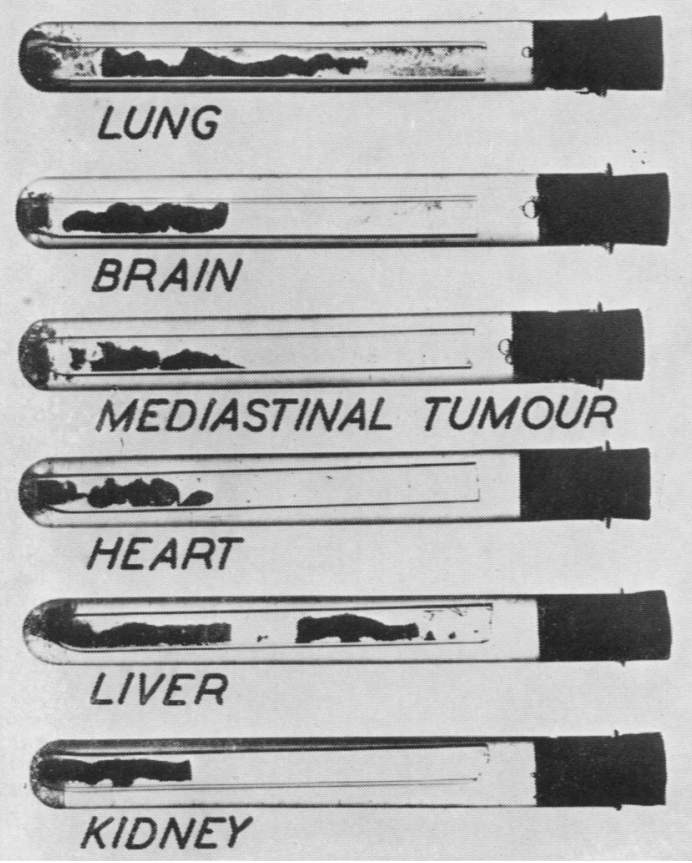

FIG. 2.-Specimens obtained by needle necropsy, each in tapered glass tubes in separate labelled test-tubes containing $10 \%$ formolsaline. ovale ; it is, however, much simpler to drill a small hole in the skull directly over the suspected area. Meningitis, encephalitis, cerebral tumours, and sometimes vascular disease may be diagnosed.

The thorax is easily accessible through the intercostal spaces. Specimens from the lungs may reveal pneumonia, phthisis, silicosis, and bronchial carcinoma, while the nature of mediastinal masses and sometimes of cardiac disease may be ascertained.

The abdomen is a rich field for needle necropsy with the liver yielding particularly good results. Hepatic specimens may disclose hepatitis, obstructive jaundice, cholangitis, fatty infiltration, cirrhosis, primary or secondary carcinoma, amyloid disease, tuberculosis, sarcoidosis, brucellosis, histoplasmosis, leishmaniasis, schistosomiasis, hydatid disease, amoebic abscess, Gaucher's disease, haemochromatosis, and polycystic disease. Needle necropsy should probably always include a specimen from the liver, whether or not clinically involved: if not enlarged, it is readily approached through the lower intercostal spaces. The spleen is less informative, except where there are deposits of lymphosarcoma, Hodgkin's disease, or other reticulosis. The kidneys are best approached through the posterior renal angles unless palpable. Renal specimens may reveal nephritis, polycystic disease, tuberculosis, and tumours. Carcinoma may be demonstrated anywhere in the intestinal tract, the pancreas, the suprarenals, the gall bladder, the urinary bladder, and in the pelvis. 
Retroperitoneal and pelvic masses may be elucidated.

Other informative sites are enlarged lymph glands, bony swellings, the vertebral bodies, and lumps in the breast.

These possible diagnoses and methods of approach are given only as guides. Individual cases will disclose many other anatomical diagnoses, while the ingenuity of the prosector will suggest other approaches suitable to the particular problem.

\section{Personal Results}

In a personal series of 24 needle necropsies, the following diagnoses have been made: Metastatic carcinoma of the liver (7), Laennez's cirrhosis (6), fatty infiltration of the liver (5), bronchial carcinoma (3) and suppurative cholangitis with secondary perisplenic abscess (1). No diagnosis was possible in two cases.

The interpretation of the specimens may require some detective ability as well as skill in histological interpretation. In one instance, the prominent features during life had been jaundice and splenomegaly. Needle necropsy revealed suppurative cholangitis, splenic tissue, and an abscess wall in separate specimens. From the information on the labelled specimen relating to site and method of approach, it was clear that the splenomegaly was in fact a normal spleen displaced by an abscess, and it was possible to make a diagnosis of cholelithiasis with suppurative cholangitis and secondary perisplenic abscess. The diagnosis was confirmed later, when permission for a full necropsy was unexpectedly granted. This case also underlines the importance of accurate and detailed labelling of the specimens.

\section{Discussion}

Most needles will, in theory, cut into tissue and obtain specimens, but in practice they are seldom successful, since they fail to detach the core at its base. Numerous instruments have therefore been devised for needle biopsy. During this investigation two of the most popular biopsy needles, the Iversen-Roholm needle (Iversen and Roholm, 1939) and the Vim-Silverman needle (Silverman, 1938) were studied, but they were considered unsatisfactory, since the specimens were frequently damaged and difficult to preserve in a condition acceptable to the pathologist, and, with the VimSilverman needle, too small.

The suggested instrument (Fig. 1) is simple to use and provides adequate material for diagnosis. The technique permits the specimens to be placed in glass tubes, where they are preserved straight and intact and are thus easier for the technician to prepare and the pathologist to examine. Once in the glass tube, the specimen can be examinedo macroscopically for the presence of carcinoma and occasionally other pathological changes. By using $\frac{\bar{m}}{\frac{1}{5}}$ a glass tube tapered at one end, not only is the $\underset{\Omega}{\mathbb{2}}$ specimen prevented from slipping out of the tube, but the pathologist knows that the tapered end ${ }^{\text {s }}$ contains the deeper portion of the specimen.

Advantages of Needle Necropsy.-The chief $\overrightarrow{\vec{\omega}}$ advantage of this procedure is that it permits post $\frac{\Omega}{2}$ mortem diagnosis when it would otherwise be? impossible. Relatives who are unwilling to permit a full necropsy will often consent to needle $\vec{\omega}$ necropsy. Relatives who permit only limited ${ }^{\infty}$

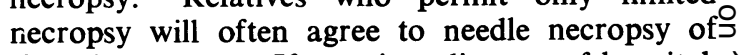
the other organs. If a patient dies out of hospital, $\vec{T}$ it is difficult to arrange for a pathologist to comed to the nursing home or private house, where the lack of facilities would in any case probably deter him from carrying out a necropsy. The problem and expense of removing a cadaver to a hospitale are usually prohibitive. The general practitionerer is seldom able to spare the time to perform such an unwonted task in a private house. Needles necropsy, on the other hand, permits the medica层 attendant to obtain diagnostic specimens in a few moments at the bedside.

Needle necropsy is also valuable when it is desired to obtain some particular tissue as soon after death as possible, even though a post-mortempermit has been signed. The post-mortem examiz nation may be delayed for several days owing to. pressure of work or statutory holidays; or the tissue, e.g., the liver, concerned may be liable tog rapid post-mortem autolysis. Under these circumstances, early needle necropsy will provide bette histological specimens than those obtained at the later formal examination.

The idea of obtaining post-mortem specimens by some form of needle or instrument is not new? Manson-Bahr (1950) refers to the value of the viscerotome in South America during the investigations of yellow fever and leishmaniasis in regions where post-mortem examinations were not pers mitted by the natives. Post-mortem specimens are obtained by biopsy needle in some institutiono where needle biopsy is practised. However, th concept of needle necropsy remains little known? and the needles available are ill-suited for the pur pose. It has therefore seemed worth while to dra attention to this procedure and to its advantages and to describe an instrument which has given th best results during a period of five years' experio mental and practical use. 


\section{Summary}

Needle necropsy is a valuable alternative to formal post-mortem examination, not only in private houses and nursing homes, but also in hospital.

An instrument suitable for needle necropsy is described and its use discussed.

My thanks are due to Mr. W. T. Harris, of W. H. Bailey and Sons, for his assistance in producing the instrument for needle necropsy, and to the Photographic Department, St. Bartholomew's Hospital, for the illustrations.

\section{REFERENCES}

Davies, G. L. (1953). Brit. med. J., 1, 1334.

Iversen, P., and Roholm, K. (1939). Acta med. scand., 102, 1.

Loewy, F. E. (1953). Brit. med. J., 1, 1163.

Manson-Bahr, P. H. (1950). Manson's Tropical Diseases, 13th ed. Cassell, London.

Silverman, I. (1938). Amer. J. Surg., 40, 671.

Terry, R. (1949). Brit. med. J., 1, 657.

Wade, M. T. (1953). Ibid.. 1, 1391. 